\section{Commentary: Carotid is the best alternative for femoral transcatheter aortic valve replacement?}

Giacomo Murana, MD, PhD, Alessandro Leone, MD, and Davide Pacini, $\mathrm{MD}, \mathrm{PhD}$

In a continually changing world, less invasive endovascular procedures modified the paradigm of standard surgical techniques. The standard access for transcatheter aortic valve replacement (TAVR) is percutaneous transfemoral (TF), because it is minimally invasive and it is associated with better clinical outcomes in comparison with all other approaches. Thanks to outstanding development of transcatheter heart valve technologies, including progressive evolution and downsizing of delivery systems and introducer sheaths, TF-TAVR is now feasible in more than $90 \%$ to $95 \%$ of patients. ${ }^{1,2}$

However, a small but not negligible group of patients is still not suitable for $\mathrm{TF}$ access due to an unfavorable vascular peripheral anatomy or tortuosity of the thoracoabdominal aorta. The Placement of Aortic Transcatheter Valves Trial II trial ${ }^{3}$ showed that the outcomes of the alternative approaches compared with $\mathrm{TF}$ access were dismal and resulted in a contamination of the general results of TAVR in this randomized trial. Interest in transapical and transaortic approaches waned, and many groups began exploring options for a safe peripheral alternative access route that can generate similar results to the TF approach, avoiding chest opening. Among the other vascular access sites for TAVR, the superficial position of the carotid artery coupled with the more complex exposure of the subclavian artery and its proximity to the brachial plexus and the

From the Cardiac Surgery Department, S Orsola Hospital, University of Bologna, Bologna, Italy.

Disclosures: The authors reported no conflicts of interest.

The Journal policy requires editors and reviewers to disclose conflicts of interest and to decline handling or reviewing manuscripts for which they may have a conflict of interest. The editors and reviewers of this article have no conflicts of interest.

Received for publication April 11, 2020; revisions received April 11, 2020; accepted for publication April 12, 2020; available ahead of print April 23, 2020.

Address for reprints: Davide Pacini, MD, PhD, Cardiac Surgery Department, S Orsola Hospital, University of Bologna, Via Massarenti 9, 40138, Bologna, Italy (E-mail: davide.pacini@aosp.bo.it).

J Thorac Cardiovasc Surg 2022;163:78-9

$0022-5223 / \$ 36.00$

Copyright (c) 2020 by The American Association for Thoracic Surgery

https://doi.org/10.1016/j.jtcvs.2020.04.054

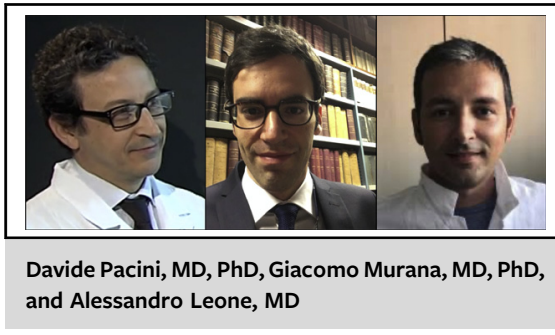

CENTRAL MESSAGE

The common carotid artery

might be a safe alternative access route for selected TAVR patients.

risks associated with its use if an ipsilateral internal thoracic artery was used as a coronary bypass graft, have led to favor of the transcarotid (TC) over the subclavian approach in selected cases. ${ }^{4}$

Junquera and colleagues ${ }^{5}$ report on a relatively underutilized arterial access by setting it against the current TF standard of care. In this single-center experience, including 526 consecutive patients undergoing TAVR, TC-TAVR was performed in 127 patients and TF-TAVR in 399 patients. The objective of the study was to compare postprocedure and 30-day clinical events in TAVR performed by TC versus TF access using a multivariate logistic regression model. The strength points of the study can be summarized as 2 main concepts.

The first is the interesting matter of debate. Similar reports have shown that TC access is associated with better outcomes when compared with transthoracic access (ie, trans-apical/aortic), but scarce data are available regarding outcomes in comparison to TF access. ${ }^{4}$ Moreover, obtaining data from a single-center experience with a large number of procedures and a standardized approach is a positive.

The second is the results. In fact, the carotid artery was a safe alternative access to perform TAVR procedures, with $98.4 \%$ procedure success and also it was noninferior compared with TF-TAVR in terms of in-hospital mortality $(3.2 \%$ vs $2.0 \% ; P=.39)$ and 30 -day stroke risk $(2.4 \%$ vs $3.3 \% ; P=.81$ ) despite a higher disease burden in TC patients. Moreover, the straight access of a TC approach allows for better control of the implantation depth of the TAVR prosthesis and could also be among the potential factor for the lower rate of postoperative pacemaker implantation in this group ( $11 \%$ and $19 \%$, respectively). 
Additionally, more frequent local vascular complications were observed in the TF group (18 patients; 4.5\%) compared with the TC group ( 3 patients; $2.4 \%$ ).

Despite all the positive aspects of the study, the main limitation of the Canadian experience ${ }^{5}$ was the lack of alternative approaches preferred in the non-TF cases. Potential drawbacks of carotid access are related to the interruption of the cerebral perfusion during valve implantation, risk of dislodging soft plaques leading to embolic strokes, presence of a small artery with the possibility of wall disruption or even the presence of contralateral carotid artery stenosis and cerebral arteriovenous malformation that may favor the occurrence of cerebral accidents. It would be interesting to compare the results of this approach with the surgical exposure of the left subclavian artery, which can be considered a second and safe alternative to TF-TAVR, considering also that there are a variety of factors to consider before an endovascular procedure, ranging from a patient's unique condition and anatomy to the skills of the team, the facility, and available technology. All of these factors needs consideration before TAVR implantation and therefore the possibility of having only 2 options can become limiting or even dangerous.

We might answer our own question; that is, Is transcarotid access the best alternative for TAVR? by pointing out that the carotid artery is a good option for TAVR but, despite single-center experiences or larger multicenter trials, the selection of the optimal access route-including the femoral artery—should always be individualized to the patient.

\section{References}

1. Mack MJ, Leon MB, Thourani VH, Makkar R, Kodali SK, Russo M, et al. Transcatheter aortic-valve replacement with a balloon-expandable valve in low-risk patients. N Engl J Med. 2019;380:1695-705.

2. Vemulapalli S, Carroll JD, Mack MJ, Li Z, Dai D, Kosinski AS, et al. Procedura volume and outcomes for transcatheter aortic-valve replacement. $N$ Engl J Med. 2019;380:2541-50.

3. Leon MB, Smith CR, Mack MJ, Makkar RR, Svensson LG, Kodali SK, et al. Transcatheter or surgical aortic-valve replacement in intermediate-risk patients. N Engl J Med. 2016;374:1609-20.

4. Chamandi C, Abi-Akar R, Rodes-Cabau J, Blanchard D, Dumont E, Spaulding C et al. Transcarotid compared with other alternative access routes for transcatheter aortic valve replacement. Circ Cardiovasc Interv. 2018;11:e06388.

5. Junquera L, Kalavrouziotis D, Côté M, Dumont E, Paradis JM, DeLarochellière R, et al. Results of transcarotid compared with transfemoral transcatheter aortic valve replacement. J Thorac Cardiovasc Surg. 2022;163:69-77.

\author{
Ko Bando, MD, $\mathrm{PhD}$
}

\section{Commentary: Finding the best alternative for transfemoral transcatheter aortic valve replacement: Is it the transcarotid approach?}

\author{
Ko Bando, MD, PhD
}

(2)

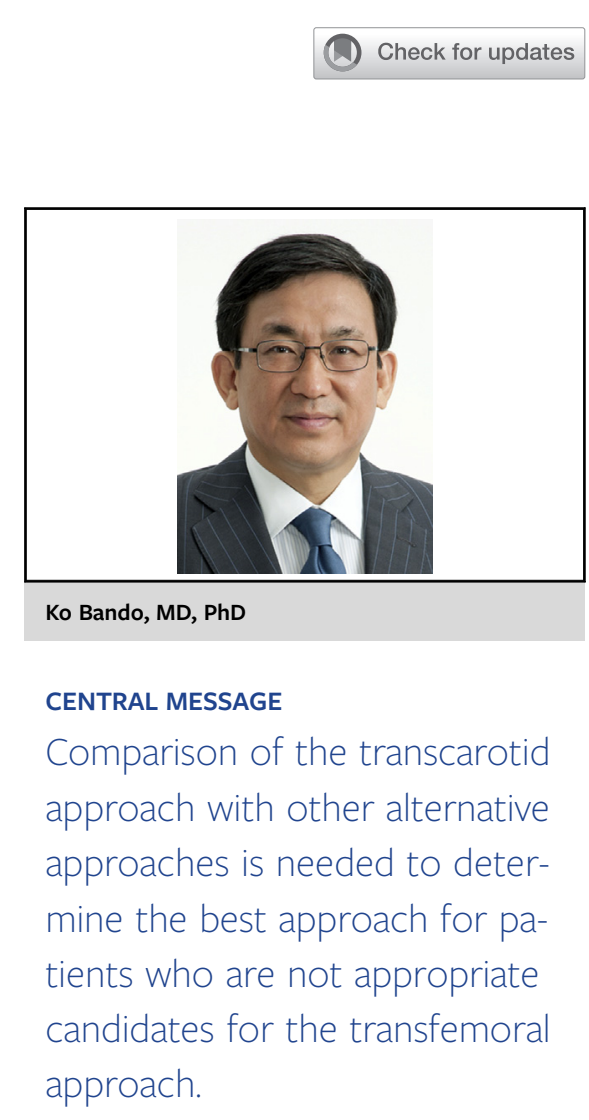

\footnotetext{
From the Department of Cardiac Surgery, The Jikei University School of Medicine, Tokyo, Japan.

Disclosures: The author reported no conflicts of interest.

The Journal policy requires editors and reviewers to disclose conflicts of interest and to decline handling or reviewing manuscripts for which they may have a conflict of interest. The editors and reviewers of this article have no conflicts of interest.

Received for publication May 14, 2020; revisions received May 14, 2020; accepted for publication May 14, 2020; available ahead of print June 1, 2020.

Address for reprints: Ko Bando, MD, PhD, Department of Cardiac Surgery, The Jikei University School of Medicine, 3-25-8, Nishi-Shimbashi, Minato-ku, Tokyo, 1058461, Japan (E-mail: kobando@jikei.ac.jp).

J Thorac Cardiovasc Surg 2022;163:79-81

$0022-5223 / \$ 36.00$

Copyright (c) 2020 by The American Association for Thoracic Surgery

https://doi.org/10.1016/j.jtcvs.2020.05.058
} 